\title{
LA INVIOLABILIDAD DEL DOMICILIO EN LAS CONSTITUCIONES ESPAÑOLAS DEL SIGLO XX
}

\author{
Silvia PASCUAL LÓPEZ
}

RESUMEN: El constitucionalismo español del siglo XX cobra pálpito en el texto republicano del 9 de diciembre de 1931; su artículo 31 será el primero que en su redacción afirme la inviolabilidad, extendiéndola a los nacionales y extranjeros residentes en España. La garantía de la intervención judicial para efectuar la entrada sólo tiene precedente en la Constitución de 1869. Todo ello otorga a ambas Constituciones el más alto rango garantista en la protección domiciliaria, a la que se sumará, con el mismo propósito, el artículo 18.2 de la vigente de 1978, funcionalmente homologable. No obstante, hemos de puntualizar que el garantismo de la Constitución de la Segunda República se vio seriamente limitado por las leyes de la Defensa de la República y de Orden Público. Los planteamientos del régimen franquista prestan atención a la inviolabilidad domiciliaria restringiéndola a los españoles, argumentando su legitimidad en mérito de unos valores que aún proclamados por el Fuero de los Españoles, raramente se respetaron. Por su parte, los constituyentes de 1978, empeñados en estructurar el Estado democrático y aquilatar las libertades, no manifiestan un interés específico sobre la inviolabilidad domiciliaria, que no sea el relativo a matizaciones sobre procedimiento.

Palabras clave: Inviolabilidad del domicilio, intervención judicial, Constitución, Estado democrático.

Fecha de recepción: 8 de noviembre de 2007 .

Fecha de dictamen: 21 de agosto de 2008.
ABSTRACT: Spanish Constitutionalism of XX Century gains flutter in the republican text of December 9th 1931; its article 31 will be the first that in its own writing affirms the inviolability, extending it into the nationals and foreign residents in Spain. The guarantee of the judicial intervention to carry out the entrance only has the precedent of the 1869 Constitution. Henceforth, all that gives both Constitutions the highest guaranteeing rank in residence protection, which will be added, with the same purpose, in article 8.2 of in force 1978, functionally enforceable. However, we have to give account that guaranteeing of Second Republic's Constitution was seriously limited by the Laws of the Defense of the Republic and Public Order. The approach of Franco's regime lay attention to the residence inviolability restricting it to the Spanish, arguing its legitimacy in merit of some values that were even proclaimed by the privilege of the Spanish, were rarely respected. In its way, the 1978 constituents, determined in structuring a democratic State and purify the liberties, cannot demonstrate an specific interest about the residence inviolability, not being related the hues about procedure.

Descriptors: Inviolability of the Home, Judicial Intervention, Constitution, Democratic State. 


\section{GARANTISMO EXCEPCIONALMENTE LIMITADO}

\section{Constitución de 1931}

A poco de proclamarse la Segunda República española (14 de abril de 1931), su Gobierno Provisional dicta un decreto (6 de mayo) por el que se crea la Comisión Jurídica Asesora, dependiente del Ministerio de Justicia, cuyo primer trabajo será la elaboración de un anteproyecto de Constitución que el gobierno, con las modificaciones que estimara pertinentes, pensaba remitir a las Cortes Constituyentes como proyecto propio. La Comisión Jurídica Asesora, por su parte, trasladará a una subcomisión, presidida por Ángel Ossorio y Gallardo, la responsabilidad de su redacción. ${ }^{1}$ Pero el gobierno no podrá remitirlo a las Cortes como proyecto propio por las disensiones producidas en el seno del propio gabinete. $^{2}$

Fracasado este intento, las Cortes designaron una Comisión Parlamentaria (28 de julio) de 21 miembros representativos de todos los grupos políticos de la Cámara, bajo la presidencia de Luis Jiménez de Asúa, para que redactase un Proyecto Constitucional, que se presentó en sede parlamentaria el 18 de agosto, texto que empezó a discutirse nueve días más tarde, para concluir el 1o. de diciembre, con aprobación definitiva el 9 de dicho mes. ${ }^{3}$

En la declaración de derechos y libertades de la Constitución de 1931 (título III) se dejan ver las influencias tanto de la Constitución me-

1 Aquel anteproyecto respondía a la tradición liberal del constitucionalismo gaditano y de las Constituciones de 1856 y 1869. Posada, Adolfo, Tratado de derecho político, Madrid, Librería General de Victoriano Suárez, 1935, t. II, p. 312.

2 Lo remitirá al Congreso como Anteproyecto de la Comisión Jurídica Asesora.

3 Véase Alcalá-Zamora, Niceto, Los defectos de la Constitución de 1931 y tres años de experiencia constitucional, Madrid, Civitas, 1981, pp. 37-50, y Meer, Fernando de, La Constitución de la II República, Pamplona, Eunsa, 1978, pp. 15-45. 


\section{xicana de $1917,{ }^{4}$ como de la alemana de Weimar de $1919,{ }^{5}$ y de la espa- ñola de 1869. \\ En ella se sitúa, como apartado 4 del artículo 31, la inviolabilidad do- miciliaria, cuyo proceso analizamos a continuación. ${ }^{6}$}

4 La Constitución de México del 5 de febrero de 1917 realiza un serio esfuerzo de integrar los derechos económicos, sociales y culturales con los civiles y políticos. Entre los derechos que regula, la inviolabilidad domiciliaria se presenta con excesivo detallismo:

"Artículo 16. Nadie puede ser molestado en su persona, familia, domicilio, papeles o posesiones, sino en virtud de mandamiento escrito de la autoridad competente, que funde y motive la causa legal del procedimiento. No podrá librarse ninguna orden de aprehensión o detención, a no ser por la autoridad judicial, sin que preceda denuncia, acusación o querella de un hecho determinado que la ley castigue con pena corporal, y sin que estén apoyadas aquéllas por declaración, bajo protesta, de persona digna de fe o por otros datos que hagan probable la responsabilidad del inculpado, hecha excepción de los casos de flagrante delito, en que cualquier persona puede aprehender al delincuente y a sus cómplices, poniéndolos, sin demora, a disposición de la autoridad inmediata. Solamente en casos urgentes, cuando no haya en el lugar ninguna autoridad judicial, tratándose de delitos que se persiguen de oficio, podrá la autoridad administrativa, bajo su más estrecha responsabilidad, decretar la detención de un acusado, poniéndolo inmediatamente a disposición de la autoridad judicial. En toda orden de cateo, que sólo la autoridad judicial podrá expedir, y que será escrita, se expresará el lugar que ha de inspeccionarse, la persona o personas que hayan de aprehenderse y los objetos que se buscan, a lo que únicamente debe limitarse la diligencia, levantándose, al concluirla, un acta circunstanciada, en presencia de dos testigos propuestos por el ocupante del lugar cateado, o en su ausencia, o negativa, por la autoridad que practique la diligencia.

"La autoridad administrativa podrá practicar visitas domiciliarias únicamente para cerciorarse de que se han cumplido los reglamentos sanitarios y de policía; y exigir la exhibición de los libros y papeles indispensables para comprobar que se han acatado las disposiciones fiscales, sujetándose, en estos casos, a las leyes respectivas y a las formalidades prescritas para los cateos".

5 En el continente europeo la expresión derechos fundamentales alcanza una importancia particular en Alemania bajo la denominación de Grundrechte. Tras la Constitución de Weimar, de 14 de agosto de 1919, se instaura un sistema de relaciones entre el individuo y el Estado que sirve de fundamento para todo orden jurídico-político. La importancia de este texto constitucional se verá reflejado en posteriores documentos que con ayuda de su influencia, pretenden encontrar un equilibrio en su sistema de derechos fundamentales, intentando conjugar libertades con los derechos económicos, sociales y culturales. El derecho a la inviolabilidad del domicilio se reconoce expresamente en su texto, cuando su artículo 115 establece: "El domicilio de un alemán es, para él, un lugar de asilo e inviolable. Sólo conforme a las leyes se admitirán excepciones".

6 La redacción definitiva del artículo 31, discutido con el núm. 29 en el Proyecto, es aprobado el mismo día de su debate, 30 de septiembre de 1931, quedando como sigue: 
La materia objeto del presente estudio quedaba configurada así en el artículo 29 del Proyecto:

El domicilio es inviolable. Nadie podrá entrar en el de un español o en el de un extranjero residente en España sino en virtud de mandamiento de juez competente. El registro de papeles y efectos se practicará siempre a presencia del interesado o de una persona de su familia, y, en su defecto, de dos vecinos del mismo pueblo. ${ }^{7}$

Este texto no varía sustancialmente del redactado en el anteproyecto, por la Comisión Jurídica Asesora, en su artículo 15. ${ }^{8}$

Al proyectado artículo 29, Eduardo Barriobero y Ramón Franco proponen sendas enmiendas consistentes en que los registros se efectúen ineludiblemente de día. Mientras el primero considera necesario añadir: "Estos registros se practicarán siempre durante el día"; el segundo aboga por introducir al final del precepto: "y siempre durante las horas comprendidas de sol a sol". ${ }^{9}$ En palabras de Barriobero:

todos hemos padecido las consecuencias de estos registros abusivos, a las tres y a las cuatro de la mañana, que, aparte de las molestias personales que ocasionan a los ciudadanos que las sufren, tienen un riesgo de vida... porque no hay ninguna defensa para aquel que a las tres de la mañana recibe en su casa

"El domicilio de todo español o extranjero residente en España es inviolable. Nadie podrá entrar en él sino en virtud de mandamiento de juez competente. El registro de papeles y efectos se practicará siempre a presencia del interesado o de una persona de su familia, y, en su defecto, de dos vecinos del mismo pueblo".

7 DSCC, 18 de agosto de 1931.

8 “... El domicilio es inviolable. Nadie podrá entrar en el de un español o de un extranjero residente en España, sino en virtud de decreto de juez competente, salvo los casos de urgencia o necesidad determinados en las leyes. El registro de papeles y efectos se practicará siempre a presencia del interesado, o de una persona de su familia, $\mathrm{y}$, en su defecto, de dos vecinos del mismo pueblo".

9 DSCC, 16 de septiembre de 1931. Enmienda al artículo 29, suscrita por los republicanos federales: Eduardo Barriobero, Joaquín Pi y Arsuaga y Emilio Niembro; los de esquerra republicana: Salvador Sediles, Antonio Jiménez y Jiménez y Ramón Franco; y el agrario: Ángel Sarmiento.

DSCC, 29 de septiembre de 1931. Enmienda al artículo 29, suscrita por los diputados de esquerra: Ramón Franco, Antonio Jiménez y Jiménez, Amadeo Aragay, Domingo Palet y Barba; los radicales socialistas: Jerónimo Gomáriz y Francisco López de Goicoechea; y el republicano federal: Eduardo Barriobero. 
la visita de la Policía, sin más testigos que aquellos que van a cumplimentar la orden. ${ }^{10}$

Enmiendas que la Comisión rechaza por entender que es indiferente la hora a la cual se efectúe el registro, si en todas ellas se causa idéntico perjuicio. ${ }^{11}$

Otro enmendante, Luis Cornide, propondrá que en la entrada y registro en domicilio se sustituya el simple mandato judicial por un acto fundado. ${ }^{12}$ En su opinión, si el proyecto constitucional prefiere determinar las garantías que deben fijarse en orden a este derecho, es imprescindible calificar técnicamente la resolución judicial que puede suspender la inviolabilidad del domicilio. El calificativo, dice, no puede ser el mandamiento - orden que un juez puede otorgar a los funcionarios de la Policía Judicial— porque el ciudadano queda supeditado a que un juez conceda una mera providencia de entrada en su morada a su agente de Policía Judicial, y, como consecuencia, sin garantía eficaz con relación a este derecho. Por ello, las palabras mandamiento judicial deben ser completadas con las de auto fundado porque en el auto, en sus resultados y considerandos han de constar los hechos y los fundamentos legales de la resolución adoptada y, por consiguiente, la posibilidad de impugnarla eficazmente. ${ }^{13}$

Esta enmienda tampoco se aceptará por plantear un dualismo innecesario en un documento constitucional más que sobrado de conceptos, reservas y palabras. Cuando la Comisión establece en el proyecto en virtud de mandamiento, dicho mandamiento ya comprende el ser expedido por juez competente. ${ }^{14}$

10 DSCC, 30 de septiembre de 1931.

11 DSCC, ibidem.

12 Texto de la enmienda: "El domicilio es inviolable. Nadie podrá entrar en el de un español o en el de un extranjero residente en España sino en virtud de auto fundado y mandamiento de juez competente. El registro de papeles y efectos sólo podrá ser acordado en auto dictado por juez competente y se practicará siempre a presencia del interesado o de una persona de su familia y, en su defecto, de dos vecinos del mismo pueblo". Enmienda presentada por Luis Cornide, Benito Blanco Rajo y Espada y Manuel Portela; los miembros de la federación republicana gallega: Alfonso Rodríguez Castelao, Antonio Villar Ponte y Ramón Otero Pedrayo; José Reino Caamaño y Leandro Pita Romero, de ORGA. Cfr. Palmer Valero, Ramón, Los problemas socioeconómicos en la Constitución de 1931, Madrid, Centro de Estudios Políticos y Constitucionales, 1997, p. 467.

13 DSCC, 30 de septiembre de 1931.

14 DSCC, ibidem. 
En el último párrafo del que será definitivo artículo 31, discutido con el número 29, procedente del 15 del anteproyecto, situado dentro del capítulo primero "Garantías individuales y políticas", se especifica:

El domicilio de todo español o extranjero residente en España es inviolable. Nadie podrá entrar en él sino en virtud de mandamiento de juez competente. El registro de papeles y efectos se practicará siempre a presencia de interesado o de una persona de su familia, $y$, en su defecto, de dos vecinos del mismo pueblo.

La inviolabilidad domiciliaria plasmada en el apartado 4 del mencionado precepto ampara por igual a españoles y extranjeros, valorándose el domicilio como una proyección de la propia persona en el espacio, siendo además el lugar en que actúa la vida familiar.

Debe advertirse que en este caso la palabra domicilio no tiene un sentido estricto, civil o administrativo, sino que equivale a vivienda, y que incluso pueden tenerlo quienes se alberguen en una fonda aunque nuestra Ley de Enjuiciamiento Criminal (artículo 557) sostenga criterio contrario. ${ }^{15}$

Así pues, la garantía que la Constitución brinda es que no baste con la orden gubernativa, sino que sea necesaria la resolución judicial para que la inviolabilidad desaparezca. En este sentido, hubiera sido preferible que la resolución fuera motivada — auto, por ejemplo - y no simple mandamiento, como se consigna.

Consecuencia de la entrada en el domicilio, y fin determinante de ella, en muchas ocasiones, es el registro de papeles y efectos que deberá ser autorizado, también, judicialmente. ${ }^{16}$

Por su parte, el Código Penal de 27 de octubre de 1932 vendrá a prohibir la entrada y registro de funcionario público que, no siendo autoridad judicial y no estando en suspenso las garantías constitucionales,

15 Pérez Serrano, Nicolás, La Constitución Española (9 Diciembre 1931). Antecedentes. Texto. Comentarios, Madrid, Editorial Revista de Derecho Privado, 1932, p. 153.

16 En los supuestos de registro, y aunque no se especifique el registro de diurnidad, la exigencia de la presencia de "dos vecinos del mismo pueblo", en defecto del interesado o de una persona de su familia", induce a pensar que el registro no había de producirse de noche. 
ejecute en el domicilio de un español o extranjero sin su consentimiento y fuera de los casos previstos en las leyes. ${ }^{17}$

Sin embargo, la Ley de Orden Público del 28 de julio de 1933, matizará esta previsión constitucional señalando en su artículo 16 tres supuestos en los cuales los agentes de la autoridad o la fuerza pública pueden entrar en un domicilio sin mandamiento judicial:

1. Cuando fueren agredidos o se atentare contra los mismos desde el domicilio en cuestión.

2. Cuando persiguiendo, inmediatamente después de cometido el delito, a un delincuente sorprendido in fraganti, se refugiase éste en su propio domicilio o en el ajeno.

3. Cuando fuese necesario prestar auxilio a las personas o evitar daños inminentes en las cosas.

Bien entendido que el acta y atestado que con tal motivo se levantaren serán entregados sin dilación a la autoridad judicial competente, a los efectos que procedan, incluso el de corregir, en su caso, las extralimitaciones que se hubiesen podido cometer. De toda extralimitación cometida se dará cuenta al gobernador civil.

Finalmente, el complemento normativo republicano, en materia de derechos fundamentales, viene constituido por la excepcionalidad limitadora de garantías derivada del artículo 42 del propio texto constitucional, regulador de la suspensión temporal de derechos (el de la inviolabilidad domiciliaria entre ellos); ${ }^{18}$ por la Ley de Defensa de la República, del 21

17 Artículo 205, inspirado en el 215 del Código Penal de 1870. El allanamiento de morada realizado por particular, en el Código Penal de 1932, es una reproducción íntegra de su precedente de 1870. La única diferencia de sus artículos 482, 483 y 484 está en el párrafo primero del precepto 482, porque a la voluntad se le añaden los términos expresa o tácita.

18 Artículo 42. "Los derechos y garantías consignados en los artículos 29, 31, 34, 38 y 39 podrán ser suspendidos total o parcialmente, en todo el territorio nacional o en parte de él, por decreto del gobierno, cuando así lo exija la seguridad del Estado, en casos de notoria e inminente gravedad.

"Si las Cortes estuviesen reunidas, resolverán sobre la suspensión acordada por el gobierno.

"Si estuviesen cerradas, el gobierno deberá convocarlas para el mismo fin en el plazo máximo de ocho días. A falta de convocatoria se reunirán automáticamente al noveno día. Las Cortes no podrán ser disueltas antes de resolver mientras subsista la suspensión de garantías. 
de octubre de 1931, durante cuya vigencia ${ }^{19}$ quedan prácticamente sin efecto las garantías, tipificándose como actos de agresión a la República no sólo formas delictuales, sino también manifestaciones de signo político cuya constitucionalidad era más que discutible; y por la Ley de Orden Público, del 28 de julio de 1933, tan restrictiva de los derechos y libertades, que la Ley del Tribunal de Garantías Constitucionales, ${ }^{20}$ en su artículo 53 prescribía:

Los recursos de amparo que se establecen como consecuencia de la aplicación de la Ley de Orden Público, en un territorio determinado, no podrán referirse más que a infracciones de aquellas garantías o derechos que la autoridad haya de respetar, a pesar de la aplicación de dicha ley...

..

Se rechazarán de plano los que se funden en causa distinta o afecten a derechos de los que sufren merma o interrupción en dichos estados excepcionales.

\section{EL DERECHO DE LA APARIENCIA}

\section{La inviolabilidad domiciliaria franquista}

El régimen del general Francisco Franco (1939-1975), surgido al término de la guerra civil, se configura al margen de la historia constitucional espa-

"Si estuvieren disueltas, el gobierno dará inmediata cuenta a la Diputación Permanente establecida en el artículo 62, que resolverá con iguales atribuciones que las Cortes.

"El plazo de suspensión de garantías constitucionales no podrá exceder de treinta días. Cualquier prórroga necesitará acuerdo previo de las Cortes o de la Diputación Permanente, en su caso. Público.

"Durante la suspensión regirá, para el territorio a que se aplique, la Ley de Orden

"En ningún caso podrá el Gobierno extrañar o deportar a los españoles, ni desterrarlos a distancia superior a 250 kilómetros de su domicilio".

19 Hasta su sustitución en julio de 1933 por la Ley de Orden Público.

20 Ley del 14 de junio de 1933. El artículo 34 de esta Ley de Orden Público, configura el estado de alarma como un grado más elevado que el estado de prevención y durante aquél, la autoridad gubernativa queda revestida de la siguiente facultad: " $f$ ) Entrar en el domicilio de cualquier español o extranjero residente en España, sin su consentimiento y examinar los papeles y efectos, siempre que ello se lleve a cabo por la misma autoridad, o por un delegado suyo, provisto de orden formal y escrita". 
ñola, por la especificidad de su naturaleza antidemocrática, que no le impide maquillar algunos aspectos entre los que se encuentran referencias al derecho objeto del presente trabajo. ${ }^{21}$

Así, en el Fuero de los Españoles, documento definidor de los derechos y deberes de los españoles y amparador de sus garantías, ${ }^{22}$ el artículo 15 contempla la inviolabilidad domiciliaria de este modo: "Nadie podrá entrar en el domicilio de un español ni efectuar registros en él sin su

21 En todo este periodo no se procede a la elaboración de una Constitución, sino que se van dictando normas concretas de diverso alcance jurídico-político, siendo las más significativas las siete leyes fundamentales:

- Fuero del Trabajo, 9 de marzo de 1938.

- Ley Constitutiva de las Cortes, 17 de julio de 1942.

- Fuero de los Españoles, 17 de julio de 1945.

- Ley del Referéndum Nacional, 22 de octubre de 1945.

- Ley de Sucesión a la Jefatura del Estado, 26 de julio de 1947.

- Ley de Principios Fundamentales del Movimiento Nacional, 17 de mayo de 1958.

- Ley Orgánica del Estado, 10 de enero de 1967.

Véase Solé Tura, Jordi, Introducción al régimen político español, Barcelona, Ariel, 1971, pp. 46-48, y Zafra Valverde, José, Régimen político de España, Pamplona, Ediciones Universidad de Navarra, 1973, pp. 179-187. Lucas Verdú, Pablo, Curso de derecho político, Madrid, Tecnos, 1976, t. III, pp. 151-154.

22 Este texto pretende la apariencia de una declaración de derechos, que se agrupan en cuatro bloques:

Derechos civiles: derecho al honor, principio normativo del respeto a la dignidad humana, libertad de conciencia, inviolabilidad del domicilio, libertad de residencia, secreto de correspondencia, seguridad personal, económica y jurídica.

Libertades públicas: derecho de libertad de expresión, derecho de reunión y asociación para fines lícitos.

Derechos políticos: derecho de petición; derecho a desempeñar cargos y funciones públicas; derecho a participar en funciones públicas; derecho a aprobar directamente, o por representantes, los impuestos.

Derechos sociales: derecho a la educación, derecho al trabajo, derecho de propiedad, derechos del trabajador.

Sin embargo, del mismo se pueden señalar demasiadas peculiaridades. Por ejemplo, que no constituya una norma directamente aplicable por los tribunales, necesitando para ello de desarrollo legislativo, que no reconozca determinados derechos fundamentales como el de asociación política, sindical o de huelga, o que pudieran ser suspendidos por un simple decreto-ley, sin control político alguno. En Esteban, Jorge de et al., Desarrollo político y Constitución Española, Barcelona, Ariel, 1973, pp. 403-452, y González-Ares, José Agustín, Introducción al estudio del constitucionalismo español (18081975), 2a. ed., Santiago de Compostela, Tórculo Ediciones, 1977, pp. 239 y 240. 
consentimiento, a no ser con mandato de la autoridad competente y en los casos y en la forma que establezcan las leyes".

La justificación de este precepto se fundamenta en la consideración de que el hombre debe ser libre no sólo en sus movimientos, sino también, de forma particular, en el refugio de sus actividades más íntimas. ${ }^{23}$ No obstante, nos situamos ante un derecho fundamental que sólo afecta a los españoles, quedando desamparados los extranjeros residentes en territorio nacional. Esta exclusión contradice la redacción del artículo 1o. de la propia ley fundamental, que proclama como principio rector de los actos del Estado el respeto a la dignidad, integridad y libertad de toda persona humana, y la del artículo 11 de la Ley de Orden Público de 30 de julio de $1959,{ }^{24}$ modificada por la Ley $36 / 1971$ de 21 de julio, al establecer que "la autoridad gubernativa y sus agentes no pueden penetrar en la morada de una persona sin su consentimiento". ${ }^{25}$

Digna de observación es la referencia al mandato de la autoridad competente que, sin proclamarlo expresamente, excluye a la autoridad judicial como legitimación jurídica de entrada en domicilio ajeno sin consentimiento de su titular. Esta formulación deja la entrada y registro domiciliario en manos del Poder Ejecutivo. La Ley de Orden Público del 30 de julio de 1959, en este sentido, aplicará el maquillaje de una terminología más homologable al referirse a mandamiento judicial. ${ }^{26}$

23 Sánchez de la Torre, Ángel, Comentario al fuero de los españoles, Madrid, Instituto de Estudios Políticos, 1975, p. 61.

24 Esta Ley 45/1959, de 30 de julio de Orden Público, se centra en la definición precisa y actual de Orden Público; la delimitación orgánica y unitaria del instrumento encargado de velar por él; el desarrollo, rigurosamente sistemático, de sus estados vitales o de crisis, reduciendo éstos a los que son racionalmente admisibles: los de excepción y guerra. En cada uno de estos últimos se ha procurado determinar los medios y el alcance de las facultades que se confieren a las autoridades gubernativas para afrontar y resolver las situaciones de emergencia que se les presente con la mínima intromisión en el libre ejercicio de los derechos personales.

25 Del mismo modo, el artículo 545 de la Ley de Enjuiciamiento Criminal (22 de junio de 1882) queda vacío de contenido en lo referente al domicilio de los extranjeros residentes en España. "Nadie podrá entrar en el domicilio de un español o extranjero residente en España sin su consentimiento, excepto en los casos y en la forma expresamente previstos en las leyes".

26 Artículo 11. "La autoridad gubernativa y sus agentes no podrán entrar en el domicilio de una persona sin su consentimiento o mandamiento judicial...". 
La suspensión del derecho a la inviolabilidad domiciliaria es una previsión del artículo 35 del Fuero de los Españoles, al decir que la vigencia del artículo 15 puede ser temporalmente suspendida por el gobierno, total o parcialmente, mediante decreto-ley. ${ }^{27}$ De nuevo, la citada Ley de Orden Público de 1959, en su artículo 11, va a contemplar las excepciones a la inviolabilidad, en aras del mantenimiento de la paz interior y el libre y pacífico ejercicio de los derechos individuales, políticos y sociales, permitiendo a la autoridad gubernativa y sus agentes entrar en el domicilio de una persona sin su consentimiento o mandamiento judicial:

Cuando sean agredidos desde él.

En los supuestos de flagrante delito, tanto para la persecución de los presuntos culpables, como para la ocupación de los instrumentos y efectos del mismo y de cuanto pueda servir para su comprobación.

Cuando en el domicilio se produzcan alteraciones que perturben el orden.

Si son requeridos por sus moradores.

Cuando sea necesario hacerlo para auxiliar a las personas o evitar daños inminentes o graves en las cosas.

Esta Ley añade que "el acta y atestado que con tal motivo se levantaren serán entregados sin dilación a la autoridad judicial competente a los efectos que procedan, incluso el de corregir en su caso las extralimitaciones que se hubiesen podido cometer. De toda extralimitación cometida se dará cuenta al gobernador civil”.

Al regular los supuestos de suspensión de derechos, el artículo 30 prevé para el estado de excepción que:

Las autoridades gubernativas pueden realizar inspecciones y registros domiciliarios en cualquier momento que se considere oportuno. [Obsérvese la contundencia que supone reforzar el registro con la inspección].

En uno y otro caso, el reconocimiento de la casa, papeles y efectos se tiene que llevar siempre a cabo en presencia del dueño o encargado, o por uno o más individuos de su familia, y por los vecinos de la propia casa o de las inmediaciones o, en su defecto, por dos vecinos del mismo pueblo.

27 Artículo 35. La vigencia de los artículos doce, trece, catorce, quince, dieciséis y dieciocho podrán ser temporalmente suspendida por el gobierno total o parcialmente mediante Decreto-Ley, que taxativamente determine el alcance y duración de la medida. 
Si en la casa no se halla el dueño o encargado de la misma ni ningún individuo de la familia, el reconocimiento se realiza en presencia de dos vecinos y se levanta acta firmada por estos últimos junto a la autoridad o delegado. ${ }^{28}$

La asistencia de los vecinos requeridos para presenciar el registro es obligatoria. (Lo habitual es disponer de vecinos afectos al régimen).

En el supuesto de no poder ser cumplido el requisito anterior, el registro se llevará a efecto haciendo constar esta circunstancia en el acta. (La fórmula da carta blanca a todo tipo de irregularidades).

Tratándose del estado de guerra, la autoridad militar es la que hace uso de dichas facultades, así como de todas las medidas pertinentes para el restablecimiento del orden o seguridad del Estado (artículo 40).

Por su parte, el artículo 14 del Decreto-Ley 10/1975, del 26 de agosto, sobre prevención del terrorismo, considera que en caso de urgencia, las fuerzas de orden público pueden proceder, previa autorización del comisario jefe o del jefe de la unidad, en su caso, al registro del domicilio o lugar cerrado, cuando se sospeche que en su interior se encuentre un individuo presuntamente responsable de alguno de los delitos a que se refiere este Decreto-Ley, o pruebas, efectos o instrumentos de los mismos. De esta medida es necesario dar cuenta inmediata al juez competente. ${ }^{29}$

Una última consideración, la remisión del artículo 15 del Fuero de los Españoles a leyes ordinarias para que sean éstas las que establezcan el procedimiento respecto a los casos y a la forma de practicar el registro domiciliario denota que, salvo la extensión de la garantía a extranjeros, todos los defectos de redacción se subsanan con lo dispuesto en la Ley de Enjuiciamiento Criminal y Código Penal del 23 de diciembre de $1944 .{ }^{30}$

28 Esta redacción tiene antecedentes en la Ley de Enjuiciamiento Criminal (22 de junio de 1882), artículo 569.

29 Esta autorización se debe expedir por escrito y con las razones de urgencia, cuya apreciación discrecional es competencia de quien la hubiera ordenado conforme al contenido del párrafo anterior. Fuera de los casos de urgencia se sigue el procedimiento ordinario. Cuando se requiera mandamiento judicial, su ejecución, conforme al artículo 563 de la Ley de Enjuiciamiento Criminal, puede delegarse a cualquier autoridad o agente de la policía judicial, quien la ejecutará asistido, al menos, de otro funcionario policial en funciones de secretario.

30 Así, la Ley de Enjuiciamiento Criminal regula la entrada y registro domiciliario de españoles y extranjeros residentes en España de acuerdo con exigencias de justicia y ajustándose a determinados límites jurídicos: auto motivado notificado a la persona afec- 
Las condiciones políticas del momento manifiestan una realidad muy divergente a la formulación legal del derecho a la inviolabilidad del domicilio. $\mathrm{El}$ hecho de que los detentadores del poder fáctico sean los que dispongan del aparato coactivo del Estado es buena muestra de ello. En consecuencia, la situación es extraordinariamente diferente a la definición de libertad domiciliaria en un régimen constitucional propio, con una auténtica protección material y formal de los derechos fundamentales.

\section{UN DEBATE CONVENCIONAL SOBRE LA INVIOLABILIDAD DOMICILIARIA}

\section{Constitución de 1978}

El tránsito de la dictadura franquista a la democracia que consagrará nuestra Constitución de 1978, tiene su punto de inflexión en las Cortes naci-

tada (artículo 550); registros domiciliarios de particulares sólo realizables durante el día, salvo que su continuación sea permitida por el interesado o su representante durante la noche (artículo 570); verificación de entrada y registro al particular interesado, en su defecto, al encargado, en su defecto, a persona mayor de edad que se halle en el domicilio (preferiblemente familiar) y, en su defecto, vecinos (artículo 566); ejecución del registro en presencia del interesado o representante y, en su defecto, de un individuo mayor de edad de su familia o de dos testigos vecinos (artículo 569); evitación, en lo posible, de inspecciones inútiles y perjuicios innecesarios (artículo 552).

El Código Penal de 23 de diciembre de 1944 castiga la entrada y registro en morada ajena realizada por funcionario público que no sea autoridad judicial, fuera de los supuestos permitidos por las leyes y en ausencia del consentimiento de su titular (artículo 191, 1 y 2). El mismo Código también recoge el allanamiento de morada y sus sanciones correspondientes, artículos 490, 491 y 492, en los mismos términos que su precedente de 1932.

“Artículo 191. Incurrirán en las penas de suspensión y multa de 1,000 a 2,500 pesetas:

"1o. El funcionario público que, no siendo autoridad judicial, entrare en el domicilio de un súbdito español sin su consentimiento fuera de los casos permitidos por las leyes.

"2o. El funcionario público que, no siendo autoridad judicial, y fuera de los casos permitidos por las leyes, registrare los papeles de un súbdito español y los efectos que se hallaren en su domicilio, a no ser que el dueño hubiere prestado su consentimiento.

"Si no devolviere al dueño, inmediatamente después del registro, los papeles y efectos registrados, las penas serán las de inhabilitación especial y multa de 2,500 a 5,000 pesetas.

"Si los sustrajere y se los apropiare, será castigado como reo de delito de robo con violencia en las personas". 
das de las elecciones generales de 15 de junio de 1977 que, aún no Constituyentes en sentido propio, ${ }^{31}$ sí determinan un auténtico proceso constituyente, singular y "sui generis", en palabras del profesor Lucas Verdú. ${ }^{32}$

Desde los debates parlamentarios, los derechos fundamentales que acabarían integrándose en el título primero de la Constitución vigente, se orientaron claramente hacia la posición que los haría derivar de los dos grandes valores del ordenamiento jurídico: la libertad y la igualdad, aportaciones del liberalismo y del socialismo democrático, lo que no impide que se postule que esos derechos fundamentales lo que de verdad pretenden son posibilitar el desarrollo integral de la persona y el ejercicio efectivo de su dignidad. ${ }^{33}$

El ejercicio de los derechos fundamentales sólo se regulará por ley, según prescripción constitucional. ${ }^{34}$ De entre éstos, los de seguridad jurídica, que dan cobertura a la inviolabilidad domiciliaria consagrada definitivamente en el artículo 18, gozan de las garantías del llamado amparo ordinario y del constitucional.

Llegado el momento de debatir la inviolabilidad del domicilio ante la Comisión de Asuntos Constitucionales y Libertades Públicas, la cuestión no despierta grandes inquietudes, sino más bien matizaciones de orden procedimental, como la que afecta al mandamiento judicial que puede franquear la entrada en un domicilio.

31 Sobre el carácter constituyente de las Cortes nacidas de estas elecciones hay división de opiniones en la doctrina constitucionalista española. Juan Ferrando Badía, lo niega. Carlos Ollero, lo afirma. "La Constitución a Debate", encuentro organizado, en febrero de 1978, para el "Club Diálogos para la Democracia", El País, semanario Cambio 16 y CITEP.

32 "Singular porque la transición del régimen franquista a la democracia liberal se ha querido hacer sin ruptura violenta, arrancando de la legalidad franquista, mediante el trámite de la 'Octava Ley Fundamental', la 'Ley para la Reforma Política'... El carácter 'sui generis' del proceso constituyente español estriba en que arranca de un pie forzado: la ley para la Reforma Politica; en consecuencia el poder constituyente encuentra mermado su calificación de originario y soberano. Arranca de una base jurídica fundamental, previa e impuesta...", Lucas Verdú, Pablo, "La singularidad del proceso constituyente español", Revista de Estudios Políticos, 1 (1978), pp. 13 y 14. Sobre este tema el profesor Lucas Verdú se extiende en su revelador trabajo La Octava Ley Fundamental. Crítica jurídico política de la Reforma Suárez, Madrid, Tecnos, 1976, pp. 13-26.

33 En este sentido, Peces-Barba Martínez, Gregorio, La Constitución Española de 1978. Un estudio de derecho y política, Valencia, Fernando Torres, 1984, p. 38.

34 Artículo 53: "1. Los derechos y libertades reconocidos en el capítulo segundo del presente título vinculan a todos los poderes públicos. Sólo por ley, que en todo caso deberá respetar su contenido esencial, podrá regularse el ejercicio de tales derechos y libertades que se tutelarán de acuerdo con lo previsto en el artículo 161, 1, a)”. 
Tal vez pueda imputarse el desinterés generalizado por la cuestión, a que la situación político-social del momento estimulaba otro tipo de atenciones, centradas en otros derechos más controvertidos, como el derecho a la vida, o la abolición de la pena de muerte.

El informe de la ponencia se limita a establecer que el registro no se realice sin mandamiento judicial. Era el punto de vista del grupo de UCD.

El anteproyecto constitucional de 5 de enero de 1978, reproduce íntegramente, en su artículo 18 apartado segundo, el artículo 21 del borrador:

El domicilio es inviolable. Ninguna investigación domiciliaria podrá realizarse sin mandato judicial.

El Informe de la Ponencia de 17 de abril, tras debatir las enmiendas presentadas al Anteproyecto y que pasamos a exponer a continuación, introduce los supuestos de flagrante delito y consentimiento expreso del titular: ${ }^{35}$

El domicilio es inviolable. Ninguna investigación domiciliaria podrá realizarse sin mandamiento judicial, salvo en el caso de flagrante delito o con consentimiento expreso del titular.

De acuerdo con la propuesta contenida en la enmienda del grupo de $\mathrm{UCD},{ }^{36}$ la ponencia, por mayoría, concede una nueva redacción, anteriormente expuesta, a este apartado.

Para ello, se acepta la enmienda de Antonio Rosón Pérez y José María Pardo Montero (UCD) basada en la sustitución del término mandato por el de mandamiento. El mandamiento judicial no equivale al mandato por incluir, este último, un concepto más restringido en el que el juez tiene que producirse motivadamente y con arreglo a las leyes del caso. ${ }^{37}$

Igualmente quedó admitida la enmienda de Jesús Sancho Rof (UCD) que planteaba, por un lado, la investigación domiciliaria con el consentimiento del propietario u ocupante $\mathrm{y}$, por otro, la previsión del hecho natural de la urgencia o flagrante delito. ${ }^{38}$

35 Sainz Moreno, Fernando (ed.), Constitución Española. Trabajos parlamentarios, Madrid, Cortes Generales, 1980, t. I, p. 517. Las enmiendas se encuentran en las pp. 166, 198, 276-277, 320-321, 359, 435, 442, 453 у 486.

36 Enmienda núm. 779.

37 Enmienda núm. 587.

38 Enmienda 716: "El domicilio es inviolable. Ninguna investigación domiciliaria podrá realizarse sin mandato judicial, salvo en los casos de evidente urgencia o por flagrante delito, según establezcan las leyes". 
Se toman en consideración, parcialmente, las enmiendas de adhesión al voto particular presentado por el Grupo Parlamentario Socialista, de Francisco Letamendia Belzunce (Grupo Parlamentario Mixto); 39 del Grupo Socialista del Congreso y de Tomás García García (Grupo Parlamentario Comunista). ${ }^{40}$ El Grupo Socialista del Congreso y el Comunista presentan, desde su punto de vista, una redacción más compresiva y garantista que la del anteproyecto. En ellas, la tutela de la inviolabilidad del domicilio se extiende a toda irrupción ilegal en el mismo, sea por causa de investigación o cualquier causa ilícita, para evitar que se pueda llegar a la injerencia, más o menos libre o sin garantías, en el derecho a la intimidad. ${ }^{41}$

El Grupo Parlamentario Socialista, a través de Pablo Castellano, enmendó en el sentido que la entrada no se efectúe sino sólo por resolución judicial motivada. Su argumentación expresa, bien a las claras, una determinación garantista:

... Porque si la Constitución queremos que vaya suponiendo un avance en la garantía de los derechos y libertades de los ciudadanos, hay que tener en cuenta que se ha producido frecuentemente, y no podemos ser ciegos a este antecedente; la corrupción de que, por una especie de rutina, eficacia o celeridad, se hayan llegado a expedir mandatos judiciales de entrada y registro casi telefónicos, que, "a posteriori" de haberse verificado, reciben la constancia escrita, lo que podríamos llamar la constancia judicial. Por consiguiente, no sobra el que en la garantía de los derechos de los ciudadanos exijamos, al tratarse de una resolución judicial, que sea previa y motivada que después acarreará una orden de entrada y registro a la Policía Judicial; pero es preceptivo exigir esa previa resolución judicial motivada, porque a lo largo de toda nuestra legislación procesal en materia de libertades del individuo se suele hacer así... con ello creo que cumplimos el deber fundamental de esta Constitución, que debe ser no desarmar a la sociedad, pero también buscar un punto de equilibrio entre ese no desarme de la sociedad y esa protección del individuo,

39 Enmienda 64.

40 Enmienda 339: "El domicilio es inviolable. Nadie podrá entrar en domicilio ajeno contra la voluntad de su morador ni efectuar registro en el mismo sin previa resolución judicial motivada".

Enmienda 703: "El domicilio es inviolable. Nadie podrá entrar en un domicilio contra la voluntad de su morador, sin previa resolución judicial motivada".

41 Guerra Fontana, Rodolfo, DS del Congreso de los Diputados, 19 de mayo de 1978. 
y creo que es un principio jurídico que el bien protegido que debe tener prioridad debe ser el del más débil, el del individuo frente al Estado. ${ }^{42}$

Gregorio Peces-Barba se extendió en las razones de la motivación, distinguiendo las tres maneras en que se manifiesta la voluntad de los jueces (providencias, autos y sentencias) para concluir que sólo el auto judicial puede equivaler a resolución judicial motivada. ${ }^{43}$

Quedó rechazada la parte de estas enmiendas que hacía referencia a la inclusión de la fórmula previa resolución judicial motivada que, por otra parte, también se argumentaba en las enmiendas del Grupo Parlamentario de Minoría Catalana ${ }^{44}$ y del Grupo Parlamentario Mixto, ${ }^{45}$ por considerar que dicha fórmula podría retrasar o no dar lugar al registro necesario, urgente y casi siempre perentorio. 46

Por último, no se aceptó la enmienda de José Miguel Ortí Bordás (UCD) que propugnaba la refundición de los apartados 2 y 3 del anteproyecto en un único apartado, evitando, de esta manera, la reiterada expresión de la exigencia de mandamiento judicial para eventuales investigaciones. ${ }^{47}$

En el Dictamen de la Comisión del 1o. de julio, aprobado por el Pleno del Congreso, se sustituirá la expresión ninguna investigación domiciliaria podrá realizarse por otra más precisa que dice ninguna entrada o registro podrá realizarse. De esta forma, el precepto se redactaba así: "El domicilio es inviolable. Ninguna entrada o registro podrá realizarse sin resolución judicial, salvo en caso de flagrante delito o con consentimiento expreso del titular".

Conforme a la enmienda de Camilo José Cela (senador de designación real), ${ }^{48}$ la Comisión del Senado de 6 de octubre vino a proponer la siguiente redacción: "El domicilio es inviolable y ninguna entrada o registro podrá

42 DS del Congreso de los Diputados, ibidem.

43 Idem.

44 Enmienda 115: "El domicilio es inviolable. Ninguna investigación domiciliaria podrá realizarse sin resolución judicial motivada".

45 Enmienda 470.

46 Vega Escandón, Luis, DS del Congreso de los Diputados, 19 de marzo de 1978.

47 Enmienda 736: "El domicilio y la libertad y el secreto de las comunicaciones postales, telegráficas y telefónicas son inviolables. Ninguna investigación podrá realizarse en las mismas sin mandato judicial".

48 Enmienda 145. 
hacerse en él sin consentimiento del titular o mandamiento judicial, salvo en caso de flagrante delito". 49

En el texto enmendante resulta verificable la alteración desde un punto de vista semántico-gramatical y la sustitución del término resolución judicial por mandamiento judicial.

Finalmente, la Comisión Mixta de 28 de octubre aprueba así la redacción definitiva del artículo 18.2: "El domicilio es inviolable. Ninguna entrada o registro podrá hacerse en él sin consentimiento del titular o resolución judicial, salvo en caso de flagrante delito".

\section{BIBLIOGRAFÍA}

AlCAlÁ-ZAmora, Niceto, Los defectos de la Constitución de 1931 y tres años de experiencia constitucional, Madrid, Civitas, 1981.

ALONSO DE ANTONIO, Ángel Luis, El derecho a la inviolabilidad domiciliaria en la Constitución Española de 1978, Madrid, Editorial Colex, 1993.

ESTEBAN, Jorge de et al., Desarrollo político y Constitución Española, Barcelona, Ariel, 1973.

Figueroa Navarro, Ma. Carmen, Aspectos de la protección del domicilio en el derecho español, Madrid, Edisofer, 1998.

GARRIDO FAlla, Fernando et al., Comentarios a la Constitución, 2a. ed., Madrid, Civitas, 1985.

GONZÁLEZ-ARES, José Agustín, Introducción al estudio del constitucionalismo español (1808-1975), 2a. ed., Santiago de Compostela, Tórculo Edicions, 1977.

GonZÁlez-Trevijano, Pedro José, La inviolabilidad del domicilio, Madrid, Tecnos, 1992.

LUCAS Verdú, Pablo, Curso de derecho político, Madrid, Tecnos, 1976, t. III.

—_ La Octava Ley Fundamental. Crítica jurídico-política de la Reforma Suárez, Madrid, Tecnos, 1976.

_- "La singularidad del proceso constituyente español", Revista de Estudios Políticos, 1, 1978. 1996.

49 Garrido Falla, Fernando et al., Comentarios a la Constitución, 2a. ed., Madrid, Civitas, 1985, p. 366. 
MATÍA PORTILLA, Francisco Javier, El derecho fundamental a la inviolabilidad del domicilio, Madrid, McGraw-Hill, 1997.

MEER, Fernando de, La Constitución de la II República, Pamplona, EUNSA, 1978.

PALMER VALERO, Ramón, Los problemas socioeconómicos en la Constitución de 1931, Madrid, Centro de Estudios Políticos y Constitucionales, 1997.

PeCeS-BARBA MartíneZ, Gregorio, La Constitución Española de 1978. Un estudio de derecho y politica, Valencia, Fernando Torres, 1984.

PÉREZ SERRANO, Nicolás, La Constitución Española (9 Diciembre 1931). Antecedentes. Texto. Comentarios, Madrid, Editorial Revista de Derecho Privado, 1932.

PosaDA, Adolfo, Tratado de derecho político, Madrid, Librería General de Victoriano Suárez, t. II, 1935.

RODRÍGUEZ SOL, Luis, Registro domiciliario y prueba ilícita, Granada, Comares, 1998.

SAINZ MORENO, Fernando (ed.), Constitución Española. Trabajos parlamentarios, Madrid, Cortes Generales, t. I, 1980.

SÁNCHEZ DE LA TORRE, Ángel, Comentario al Fuero de los Españoles, Madrid, Instituto de Estudios Políticos, 1975.

SOLÉ TURA, Jordi, Introducción al régimen politico español, Barcelona, Ariel, 1971.

ZAFRA VALVERDE, José, Régimen político de España, Pamplona, Ediciones Universidad de Navarra, 1973. 